\title{
Improving the worldwide quality of nuclear cardiology practice and research: The role of the official journal
}

\author{
Keiichiro Yoshinaga, MD, PhD, FACC, FASNC, ${ }^{a}$ and Nagara Tamaki, MD, PhD ${ }^{b}$ \\ a Diagnostic and Therapeutic Nuclear Medicine, National Institute of Radiological Sciences, \\ Chiba, Japan \\ b Department of Nuclear Medicine, Hokkaido University Graduate School of Medicine, Sapporo, \\ Japan
}

Received Aug 16, 2016; accepted Aug 17, 2016

doi: 10.1007/s12350-016-0655-4

\begin{abstract}
The object of art is not to reproduce reality, but to create a reality of the same intensity
\end{abstract}

-Alberto Giacometti-

One of the highlights of American Society of Nuclear Cardiology (ASNC) 2015 in Washington DC was intense discussions in the international sessions. Nuclear cardiologists from Europe, South America, the Middle East and Asia, and core ASNC officials attended this session. Speakers from around the world described the current status of nuclear cardiology in their regions and talked about region-specific diseases. ${ }^{1,2}$ The ASNC, through its inclusion of the international session, hopes to become a truly international society. Further, in order to do so, it is important to seek new members from outside of the US. As of July 2016, the total ASNC membership was 3698, a figure that has been stable since 2011. While the number of ASNC members from outside of North America has grown by $25 \%$ since 2013 due to a new membership category initiated by ASNC in that year, the total non-North American membership is still quite small, with Americans continuing to make up $89.9 \%$ of members. Standards of current clinical practice and research within nuclear cardiology are quite high thanks to the efforts of ASNC. ${ }^{3}$ In other parts of the world, however, improvements in terms of the quality of clinical practice and research activities within the field of nuclear

Reprint requests: Nagara Tamaki, MD, PhD, Department of Nuclear Medicine, Hokkaido University Graduate School of Medicine, Sapporo, Japan; natamaki@med.hokudai.ac.jp

J Nucl Cardiol 2017;24:335-7.

1071-3581/\$34.00

Copyright (C) 2016 American Society of Nuclear Cardiology. cardiology are needed. Through the ASNC 2015 international sessions, we have also recognized the gaps between the US and some regions around the world. Therefore, the mission of ASNC continues to be to expand and to raise the quality of nuclear cardiology around the world.

\section{ROLE OF THE SCIENTIFIC JOURNAL IN RAISING THE QUALITY OF NUCLEAR CARDIOLOGY WORLDWIDE}

There are several approaches to providing educational opportunities and to delivering educational products to nuclear cardiologists around the world. These include scientific meetings, websites, international fellowships in North America or Europe, textbooks, and official scientific journals. As Erthal et al. noted, fellowship training programs in North America or Europe are among the best ways to raise the quality of nuclear cardiology at a personal level. ${ }^{4}$ This seems to be the best way to do so, and several of our Japanese colleagues have participated in fellowship programs in North America. ${ }^{5}$ In fact, nuclear cardiologists with fellowship training have made great contributions to raising the quality of nuclear cardiology in Japan. ${ }^{1}$ As Erthal et al. mentioned, those aiming to take part in a fellowship program have to overcome several issues, the most challenging of which is to obtain a work permit (i.e., visa). It is true that increasing the number of international fellowship positions means contributing to job losses in North America or Europe. Therefore, applicants must compete with members of the job markets in North America or Europe, and the competition is getting tougher and tougher. As a result, a very limited number of fellows get to have these prestigious opportunities. Participating in the ASNC 
scientific meeting or other scientific meetings also presents significant opportunities for nuclear cardiologists to learn about the latest guidelines on procedures, to attend several educational sessions, and to present their own findings to top researchers. As I mentioned, ASNC has successfully increased the number of participants from outside North America by having international sessions at ASNC and at the International Congress of Nuclear Cardiology and Computed Tomography (ICNC). ${ }^{6}$ ASNC 2015 in Washington DC had a total of 831 participants from 36 countries, and $136(16.4 \%)$ of those were from outside of North America. A total of 82 abstracts were presented, 21 (25.9\%) by non-US nuclear cardiologists. JNC received a total of 637 manuscripts between January 1, 2014 and December 31, 2015. Of these, 308 (48.4\%) came from outside of the US and originated from a total of 42 different countries. These statistics show that JNC is receiving ever more manuscripts from outside of the US rather than from the annual meeting of ASNC. The Japanese Society of Nuclear Cardiology (JSNC) is also aiming to develop international activities. As the initial step toward doing so, JSNC hosted the first ASNC/ JSNC joint session at this year's annual meeting and invited two guests from outside of Japan. JSNC members and ASNC members discussed how we should work together to promote cardiac sympathetic nervous system imaging in the US and Europe as the initial step in international collaborations. ${ }^{7}$ However, only $0.6 \%$ of participants were from outside of Japan. With a view to increasing its international presence, JSNC also launched a new English-format journal, the Annals of Nuclear Cardiology (ANC). Among 23 manuscripts in the first issue of ANC, $5(22.7 \%)$ were submitted from outside of Japan, from countries including the US, Canada, and Germany. Although one cannot make a direct comparison between the number of nuclear cardiologists from outside of Japan or the US hosted by the ASNC or JSNC at its annual conference and the number contributing to an official journal, these data may indicate that official journals play an important role in promoting international activities of societies. These data may also indicate that one role of an official journal is to allow for communication among nuclear cardiologists from several countries.

Dr. Iskandrian took over the role of Editor-in-chief of the Journal of Nuclear Cardiology (JNC) in 2014. More than a year has passed since then, and Dr. Iskandrian has introduced several new corners in JNC, including the international corner and educational corners. ${ }^{8}$ These new sections and articles in these sections will definitely contribute to raising the quality of nuclear cardiology around the world. While it may be true that attending conferences and hearing lectures can have significant educational effects, manuscripts reporting the highlights of these conferences do not simply list the contents of these presentations but rather, as Giacometti described, capture the intensity of the contents of these presentations. This is the value of each article published by scientific journals.

Accessing JNC is now much easier than it was decades ago. We can get hold of articles published by JNC via PubMed or other search tools such as Google Scholar. ASNC offers a special "International" membership category. With an international membership, nuclear cardiologists from around the world have online access to state-of-the-art scientific manuscripts, educational articles, imaging guidelines, and conference proceedings. In addition, nuclear cardiologists can learn about the exciting discussions held at conferences even without being in attendance.

When ASNC launched JNC, all editorial board members focused on getting high-quality content into the journal. By committing to publishing excellent content, JNC promised to be a high-quality journal. Such a simple rule still applies to any scientific journal. The question of standards of journals has recently become even more complex as each journal vies for ranking with journals in the same scientific category according to level of impact factor and authority. JNC focuses on very specific topics and therefore may not have broad readership. In this regard, opportunities to be cited may be limited compared to those for other journals in the same category (i.e., radiology or cardiology). ${ }^{9}$ However, it is also important to increase its scholarly value ranking among radiology and cardiology journals. Considering the mission of ASNC, JNC needs to continue to publish educational articles as it is currently doing. At the same time, JNC also needs to maintain a high standard of competence. In order to achieve this goal, we must submit our best scientific manuscripts to JNC to raise the quality of the journal. Therefore, JNC may not be able to publish very basic educational manuscripts for fellows and residents. ${ }^{10}$ JNC may also not be able to publish manuscripts involving very preliminary data. As I mentioned before, JSNC has launched a new English-format official journal, ANC. ${ }^{11}$ ANC can also be accessed via its website (www.jsnc.org/annals-nuclear-cardiology). We believe that ANC's role is to support or complement that of JNC. Japanese nuclear cardiologists have learned much from ASNC in a sort of "East meets West" kind of way. JSNC is now hoping to spread our experiences and knowledge to other regions and is now aiming to work together with several countries through this new journal with the idea of "East extending its reach." In this regard, the role of official journals in 
nuclear cardiology is becoming more and more important.

\section{Disclosure}

None.

\section{References}

1. Yoshinaga K, Tamaki N. Current status of nuclear cardiology in Japan: Ongoing efforts to improve clinical standards and to establish evidence. J Nucl Cardiol. 2015;22:690-9.

2. Ishida Y, Yoshinaga K, Miyagawa M, Moroi M, Kondoh C, Kiso K, Kumita S. Recommendations for (18)F-fluorodeoxyglucose positron emission tomography imaging for cardiac sarcoidosis. Ann Nucl Med. 2014;28:393-403.

3. Dilsizian V, Arrighi JA, Cohen RS, Miller TD, Solomon AJ, Udelson JE. COCATS 4 Task Force 6: Training in nuclear cardiology. J Am Coll Cardiol. 2015;65:1800-9.
4. Erthal F, Beanlands R. The journey of international fellows: Have you been to America? J Nucl Cardiol. 2015;22:1161-2.

5. Ohira H, Beanlands R, Chow BJ. The cardiac imaging fellowship training program at the University of Ottawa Heart Institute. Ann Nucl Cardiol. 2015;1:103-5.

6. Kitsiou A, Dorbala S, Scholte AJ. Highlights of the 12th international conference on nuclear cardiology and cardiac CT. J Nucl Cardiol. 2015;22:866-73.

7. Yoshinaga K, Chikamori T. Focus issue on cardiac sympathetic nervous system imaging from JSNC/ASNC Joint Session in 26th JSNC Annual Scientific Meeting. Ann Nucl Cardiol. 2016;2: 136-7.

8. Iskandrian AE. One year retrospective anniversary. J Nucl Cardiol. 2015;22:1-2.

9. Iskandrian A. The Journal of Nuclear Cardiology and the changing guards. J Nucl Cardiol. 2015;21:1-2.

10. Iskandrian A. The art and science of writing a scientific manuscript. Ann Nucl Cardiol. 2015;1:3-5.

11. Yoshinaga K. Time to move on to the next stage and open our door to the world. Ann Nucl Cardiol. 2015;1:1-2. 